\title{
New direction recommended for isotope production
}

Published at www.cmaj.ca on Dec. 7, 2009

I $f$ the federal government implements the recommendations of an expert panel on isotope production, Canada will be moving in the opposite direction of the approach used by MDS Nordion and Atomic Energy of Canada Ltd. (AECL) - and that's a good thing, says a US nuclear expert and long-time critic of Canada's isotope production practices.

"The 4 general recommendations are a repudiation across-the-board of the Nordion/AECL approach," Alan J. Kuperman, director of the Nuclear Proliferation Prevention Program at the University of Texas at Austin, wrote in an email.

The report, which was prepared by a government-appointed panel of nuclear experts, was submitted to Natural Resources Minister Lisa Raitt on Nov. 30,2009 , and released to the public on Dec. 3, 2009, (http://nrcan.gc.ca/eneene /sources/uranuc/pdf/panrep-rapexp-eng .pdf). The office of the natural resources minister stated that no comments on the report or the panel's recommendations would be made at the time.

Though Canada's isotope production capabilities are fragile, creating isotopes is complex and there is no quick fix, the panel suggests in the report. Still, it makes four general recommendations on how to address the problem:

- More players should be introduced to the medical isotope distribution chain, now dominated in North America by MDS Nordion, a life sciences company based in Ottawa, Ontario. The isotope used in most diagnostic imaging tests, technetium-99m, is a perishable product and therefore the security of supply can only be achieved "through excess capacity, redundancy and diversity," the report states.

- The federal government should work with other countries to better coordinate worldwide production and distribution of medical isotopes. In the

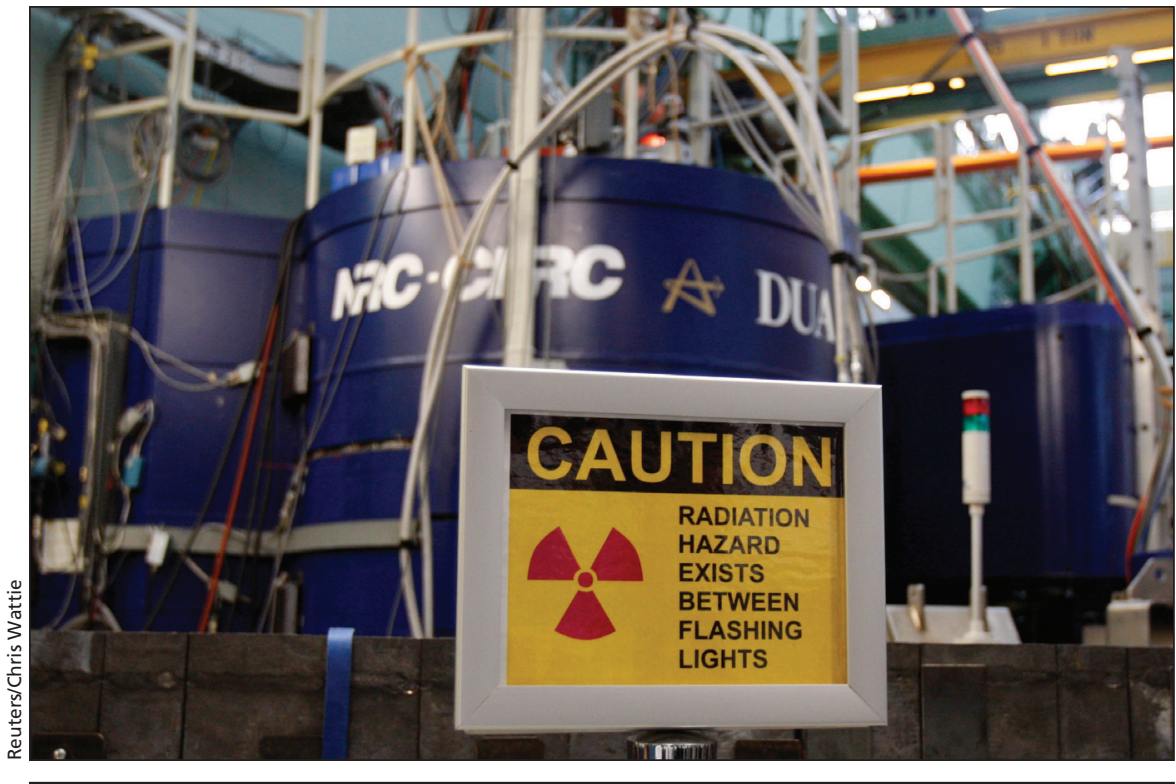

Some nuclear medicine physicians question an expert panel's recommendation to build a new nuclear reactor in Canada, claiming the government has yet to prove that two existing reactors in Chalk River, Ontario, are not viable.

past, members of the European nuclear medicine community have accused Canada of being unwilling to participate in the creation of a global contingency plan (CMAJ 2008. DOI:10.1503/cmaj.080154).

- Canada should eventually shift to making isotopes with low-enriched uranium targets. Canada's aging National Research Universal reactor, whose frequent and extended shut-downs have caused isotope shortages, uses highly enriched uranium, as does the scrapped MAPLE (Multipurpose Applied Physics Lattice Experiment) reactors.

- Canada should build a new multipurpose reactor. Unlike the MAPLE reactors in Chalk River, Ontario built by AECL specifically to produce medical isotopes, but which remain offline because of technical problems - a multipurpose reactor could be used for other activities, such as research.

"A multipurpose reactor makes a lot of sense," says Dr. Christopher O'Brien, president of the Ontario Association of
Nuclear Medicine. "It will ensure Canada has significant research capabilities."

Such a reactor would be more economically viable because costs would be shared over more activities, the report states. The upfront costs, however, would be substantial - somewhere between $\$ 500$ million and $\$ 1.2$ billion, the panel estimates. Annual operating costs would likely be between $\$ 45$ million and $\$ 70$ million.

"The uncertainties about such a project are mainly economic, not technical," wrote Kuperman. "A new reactor would be expensive to construct. Moreover, by the time it could produce isotopes, several other new production facilities should be on line worldwide, including in the United States and the Netherlands. Thus, it is not clear that Canadian sales of Mo-99 [molybdenum99, the parent isotope of technetium-99] could recoup the cost of the reactor and associated production facilities."

Nonproliferation advocates, such as Kuperman, applaud the recommendation to eliminate highly enriched uranium from civilian use. 
"Adoption of such a policy would reinstate Canada's global leadership role on nuclear nonproliferation, replacing Nordion/AECL's regrettable policy of undermining international nonproliferation norms by perpetuating risky commerce in bomb-grade uranium," he writes.

One recommendation is notably absent from the report: reviving the MAPLEs project. The panel appears leery of this approach, stating that "the ongoing economics for this project remain questionable." Kuperman agrees, citing the high costs that would be required to convert the reactors to use low-enriched uranium.

O'Brien, on the other hand, would like to see the controversial project undergo a review by an independent panel of experts before abandoning it altogether.

"Let's get an unbiased opinion of the MAPLEs," says O'Brien. "We've been calling for this for over a year. Let's get an impartial panel to put this controversy to bed."

This opinion is shared by Dr. Jean-
Luc Urbain, president of the Canadian Association of Nuclear Medicine. Creation of a new reactor would only be preferable to reviving the MAPLE project if the federal government proves the MAPLE reactors aren't viable, which, he says, it has yet to do.

"What is very paradoxical is proposing a brand new reactor," Urbain says. "Why spend $\$ 500$ million when you can spend $\$ 100000$ to bring in an international panel of experts to review the MAPLE reactors? It makes absolutely no sense to me."

O'Brien is encouraged, though, by the panel's suggestion to explore greater use of cyclotrons to produce technetium-99m. Cyclotrons are smaller and cheaper than nuclear reactors, and the infrastructure is already in place in some parts of Canada. An advantage of this option, the panel suggests, is that cyclotrons can also be used for isotope research and to produce positron emission tomography isotopes.

One problem with using cyclotrons is that they directly produce technetium-99m, which has a very short half-life - unlike the National Research Universal reactor, which produces the longer-lasting parent isotope molybdenum-99. This would make distribution a challenge. Still, cyclotrons could potentially serve as a backup, says O'Brien, and at least supply medical isotopes to urban centres.

Urbain, however, says that cyclotrons are not yet a viable option. "The report is overly optimist about making technetium-99m using cyclotrons," he says. "In order to produce meaningful amounts of technetium-99m, the cyclotron needs to be so powerful that it makes it very impractical."

Another problem, Urbain notes, is the lack of established methods to process isotopes produced by cyclotrons. As a whole, the expert panel's report offers little of value, says Urbain. "The report is very comprehensive but doesn't bring anything new to the table." - Roger Collier, CMAJ

DOI:10.1503/cmaj.109-3127 